\title{
COMUNIDAD AVIAR Y CAMBIOS DE USO DEL SUELO EN EL PIEDEMONTE DEL SISTEMA IBÉRICO (COMARCA DE BORJA, ZARAGOZA- ESPAÑA)
}

\author{
Roberto SERRANO NOTIVOLI - Luis Alberto LONGARES ALADRÉN \\ Dpto. Geografía y O.T. Universidad de Zaragoza
}

Recibido: 10/05/2011

Devuelto: 07/07/2011

Aceptado: 07/02/2012

RESUMEN: Se estudia la comunidad aviar presente en el sector de piedemonte del Sistema Ibérico zaragozano que forma parte de la Comarca del Campo de Borja (Zaragoza, España), durante la época invernal y reproductora. Se analizan los parámetros de Diversidad, Riqueza específica y Constancia para el conjunto del área de estudio, así como para el humedal artificial conocido como "La Estanca de Borja". Además se procede al análisis de los cambios observados en la composición de esta comunidad aviar entre 1970 y 2009, comparándolos con los cambios que se han producido durante dicho periodo en cuanto al uso del territorio y los hábitats establecidos para el estudio de la dinámica temporal de los mismos.

PALABRAS CLAVE: Comunidad aviar, Diversidad, Riqueza, Constancia, Usos del suelo, Dinámica comunidades, Estanca, Borja, Zaragoza.

AVIAN COMMUNITIES AND CHANGES IN LAND USE IN THE FOOTHILLS OF THE IBERIAN SYSTEM (BORJA REGION, ZARAGOZA, SPAIN)

ABSTRACT: In this paper, is analyzed the avian community in piedmont of Iberic range in Saragossa province, which is part of Campo de Borja Region (Saragossa, Spain), along wintering and breeding season. Diversity, Specific richness, and Constancy parameters are analyzed to all study area and to an artificial wetland called "La Estanca de Borja". Also are analized the observed changes in avian community composition between 1970 and 2009, comparing them with changes in land uses and habitats in that period to study the temporal dynamics of them.

KEY WORDS: Avian community, Diversity, Richness, Constancy, Land use, Community dynamics, swamp, Borja, Saragossa.

\section{I) INTRODUCCIÓN}

Las diferentes dinámicas paisajísticas que se han sucedido en la Península Ibérica a lo largo de la segunda mitad del siglo XX y la primera década del 
XXI, obedecen en gran medida a procesos de cambios de uso por parte de la actividad humana, abandono de la actividad agrícola y ganadera y/o grandes incendios forestales (VALLADARES, 2004; LASANTA et AL., 2005; VILA et $A L$., 2009). Como resultado de todo ello se ha producido la fragmentación y variación en el reparto, estructura y composición de los hábitats que conforman un territorio, dando lugar a cambios en la distribución de las especies y por tanto de la diversidad (SANTOS y TELLERÍA, 2006).

En este contexto, el grupo de las aves, por su rápida respuesta a los cambios ambientales (FURNES y GREENWOOD, 1993; SANTOS, 2004; PADOASCHIOPPA et $A L$., 2006), ha sido utilizado en numerosas ocasiones como indicador de estos cambios, por lo que constituye una buena herramienta para el seguimiento, control y análisis de los mismos. Sin embargo, en el ámbito de análisis de dinámicas temporales y cambios en el paisaje, no es frecuente poder contar con datos precisos de la comunidad aviar de un territorio concreto y que además abarque un periodo de tiempo amplio como para que puedan servir como indicadores de dichos cambios.

Con motivo de la elaboración de un inventario ambiental en la comarca de Borja (Zaragoza), se obtuvieron datos sobre la avifauna presente en este territorio en 2009, comprobando que existía bibliografía que recogía trabajos previos en la zona, que ofrecían información muy valiosa y de indudable calidad (PELAYO, 1978 y 1991) y que abrían la posibilidad de analizar los cambios acaecidos en el grupo de las aves en este espacio para un periodo de tiempo de más de 30 años.

Los citados estudios de Pelayo nos han permitido contar con datos acerca de las aves nidificantes presentes durante los años 70 para un contexto amplio como son la Comarca del Moncayo y Campo de Borja, dentro de la que se sitúa la zona de estudio (MAPA 1), y más en concreto sobre la comunidad aviar presente en la Estanca de Borja y entorno próximo, en la que el autor ya citaba más de cien especies tan sólo para este espacio.

Por otra parte desde principios de los años 90, se dispone de información sobre el conjunto de aves reproductoras, ya que a finales de la década de los 80, se lleva a cabo el trabajo de campo que permite la publicación del primer atlas de especies nidificantes de la Comunidad de Aragón (SAMPIETRO et $A L ., 1998)$, y que plantea, mediante una metodología de censos en hábitats estandarizados y en base a una superficie de cuadrículas de 10 x $10 \mathrm{~km}$., la prospección del conjunto de aves reproductoras, que constata la presencia de al menos diecisiete especies diferentes. 


\section{II) ÁREA DE ESTUDIO}

El área de estudio se localiza en el sector del piedemonte del sistema ibérico zaragozano (MAPA 1), próximo al macizo del Moncayo y en un espacio de transición entre la llanura de inundación del Ebro y los relieves tabulares típicos del centro de la depresión del Ebro.

Se trata de un espacio que abarca una superficie aproximada de $108 \mathrm{~km}^{2}$, dominado paisajísticamente por un mosaico de cultivos en la zona suroeste, en la que el viñedo se alterna con formaciones de matorral sub-arbustivo y rodales de masas arbóreas de tamaño pequeño o mediano. Hacia el Noreste, el Canal de Lodosa divide dos ambientes agrícolas, dejando en la zona occidental grandes extensiones de secano, y abarcando toda la longitud del Canal los cultivos de regadío, en la zona oriental. El clima en este territorio aporta unos matices continentales propios que se suman a la caracterización general del clima mediterráneo de la depresión del Ebro, dominado por una irregularidad y variabilidad de las precipitaciones, contrastes térmicos acusados, y especialmente aridez, que condiciona fuertemente el paisaje agrario del entorno.

El paisaje mixto agrícola-natural, presente en el cuadrante Suroeste de la zona de estudio, es el que alberga mayor diversidad de elementos (comunidades de matorral, las masas arbóreas del piedemonte de La Muela de Borja, y una compactada zona de cultivos de regadío y viñedo), todos ellos organizados en torno a La Estanca de Borja. Ésta se configura en la zona como un espacio húmedo de gran importancia dentro de un entorno semiárido, dado que el punto de agua permanente más cercano es el propio río Ebro a más de $10 \mathrm{~km}$. al Noreste, y las características climáticas propician una escasez crónica de precipitaciones, este espacio es un punto de confluencia de gran importancia en las rutas de las aves migratorias, especialmente de las ligadas a medios acuáticos.

Sin ser un espacio fuertemente antropizado, las infraestructuras ligadas al aprovechamiento del territorio están muy presentes en el entorno, especialmente la instalación de aerogeneradores y líneas de media y alta tensión que han ocupado progresivamente el entorno durante la última década.

\section{III) MATERIAL Y MÉTODOS}

\section{III.1. Censos y taxiados}

El conocimiento actual del conjunto de aves presentes en la zona de estudio, se obtiene mediante la campaña de campo que tiene como punto de partida diciembre de 2008, y que se continúa a lo largo de 2009 hasta alcanzar el final de la primavera de este último año. Durante este espacio de tiempo, 
se realizaron censos en La Estanca de Borja, así como taxiados en el entorno próximo.

\section{Mapa 1. Localización de la zona de estudio}

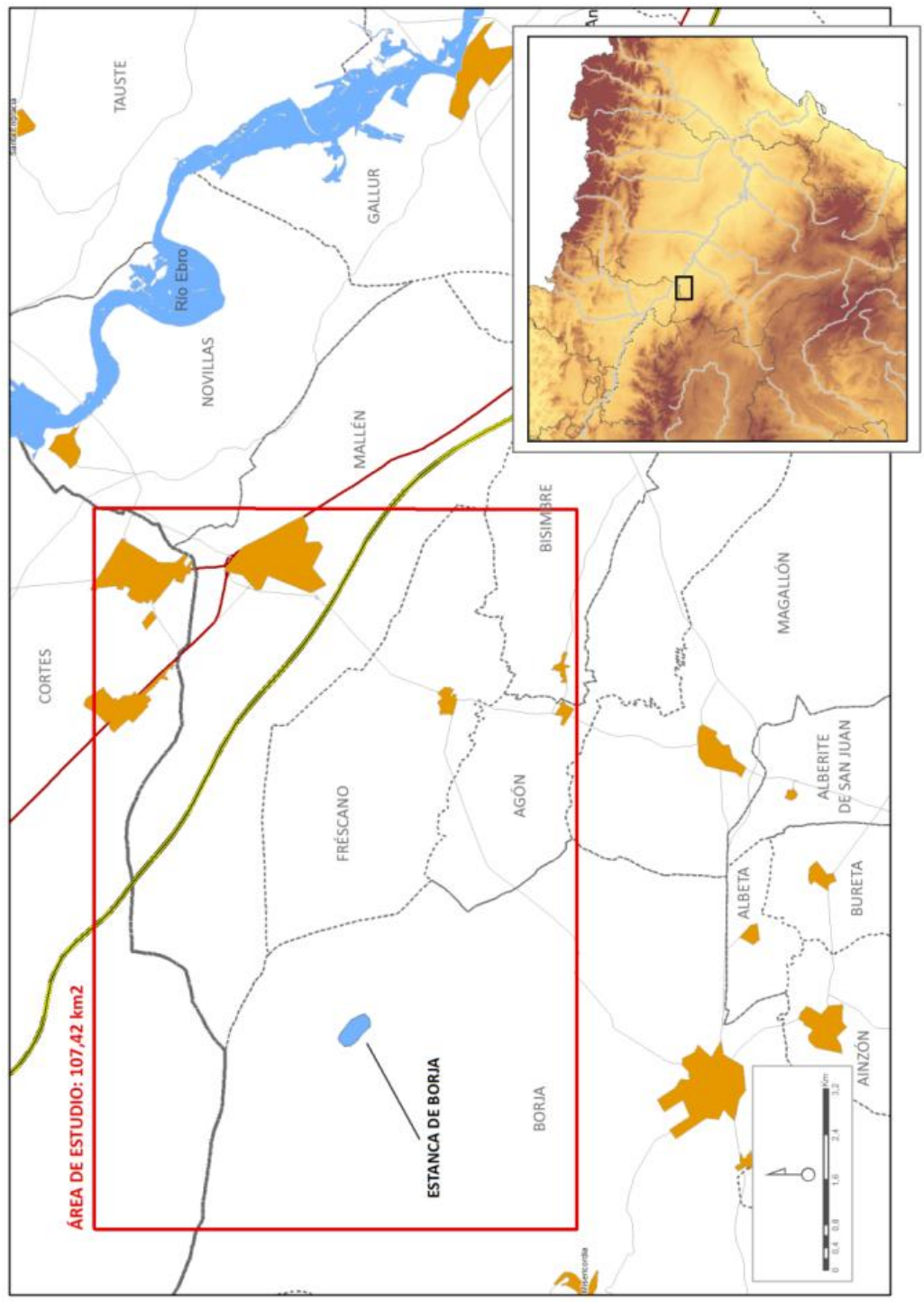

Se procedió a prospectar toda la zona en un radio aproximado de $10 \mathrm{~km}$. desde el punto de agua de la Estanca, con horario diurno para las aves inver- 
nantes de noviembre a febrero, y con horario combinado desde marzo hasta mayo, con sesiones de periodicidad semanal, en las que se tomaron anotaciones de paso y conducta de las aves, así como la dirección e intensidad del viento reinante en esos momentos.

Se realizaron un total de 25 jornadas de campo, en las que se plantearon dos métodos de trabajo. Por un lado, 19 estaciones de censo de 20 minutos en dos puntos de La Estanca de Borja, y 28 taxiados en banda de $25 \mathrm{~m}$. (JARVINEN y VAISANEN, 1975, TELLERÍA, 1978 y 1986; TELLERÍA y GARZA, 1983).

Mediante el método de taxiado se recorrieron un total de 95 kilómetros, abarcando una superficie de 479 hectáreas, en los que se prospectaron todas las aves observadas en una banda de 25 metros a ambos lados del transecto recorrido. Al mismo tiempo, se procedió a la búsqueda de restos de aves en lugares puntuales que se consideraron de importancia, especialmente edificaciones agrícolas abandonadas, muy presentes en la zona de estudio y de gran importancia para especies como Falco naumanni (cernícalo primilla), que en el valle del Ebro tiene total dependencia de estas construcciones agroganaderas (AlCÁNTARA y GAJÓN, 2004), así como para la Pyrrocorax pyhrrocorax (chova piquirroja) habitual también de estos enclaves en ambientes semiáridos aragoneses (GAJÓN et AL., 2004).

\section{III.2. Cartografía de usos del suelo}

Para conocer los cambios acaecidos en el paisaje durante el periodo analizado, se realizó cartografía de usos del suelo en tres periodos diferentes (1957-1980, 1980-1990 y 1990-2009) coincidiendo con las fechas de estudio de las que se disponían datos sobre la comunidad de aves. Esta cartografía se realizó en formato digital y bajo soporte del Sistema de Información Geográfica ArcGis 9.3, con licencia del Dpto. de Geografía de la Universidad de Zaragoza.

Para el año 1970, se tomó como referencia el periodo de cambio entre 1957-1980, para lo cual se procedió al escaneado en alta resolución y posterior georreferenciación de los fotogramas existentes para la zona del vuelo americano de 1957, en formato de blanco y negro, a la que siguió el trabajo de fotointerpretación de las ortoimágenes y posterior digitalización en la plataforma SIG ya citada disponibles, procediendo a la corrección de las categorías de suelo resultantes. Este trabajo, fue comparado y completado mediante el servicio Web Map Server (WMS) del Ministerio de Medio Ambiente, Medio Rural y Marino en el que está disponible la consulta del Mapa 
de Cultivos y aprovechamientos de 1980 a escala 1:50.000, y de los mapas de aprovechamientos que fueron utilizados para los periodos posteriores.

El mapa de usos del suelo del año 1990 se realizó a través de una adaptación de la cartografía vectorial del Corine Land Cover 1990 (nivel 3), y el Mapa de Mapa de Cultivos y aprovechamientos de 1990, reajustando de nuevo el nivel de detalle del mapa de usos de 1970 realizado antes. La cartografía de usos del año 2009 se realizó íntegramente a través de fotointerpretación directa mediante los fotogramas disponibles en el WMS del Gobierno de Aragón que corresponden Plan Nacional de Ortofotografía Aérea (PNOA) 2009 , además de ser validadas en campo las zonas que mayor dificultad presentaban sobre la imagen aérea.

El nivel de detalle de la cartografía de usos del suelo se consideró suficiente para los objetivos del trabajo, principalmente el de asociar los usos del suelo a los hábitats dominantes en la zona de estudio.

\section{III.3. Integración de los datos en un SIG y análisis}

Con el fin de observar de manera integradora todos los elementos que componen el territorio, y los factores que pueden afectar a los patrones de distribución de las comunidades de aves, se incorporó la información a un Sistema de Información Geográfica (SIG), en el que se desarrollaron las cartografías de usos del suelo para los diferentes periodos considerados, y se analizaron los cambios en los mismos. Con estos cambios se definieron dos escenarios cartográficos para los periodos 1970-1990, y 1990-2009, presentando dos momentos comparables con los datos de distribución de las especies de aves.

Para evaluar los cambios entre el primer periodo y el segundo, y entre el segundo y el tercero, primero se cartografiaron las unidades de usos del suelo de los tres periodos con las fuentes explicadas en el apartado anterior; después, en formato ráster, se asignaron los mismos valores únicos (de 1 a 9) a cada categoría del suelo en cada periodo; y por último se realizaron los cálculos mediante la herramienta "Raster calculator" de la extensión "Spatial Analyst" de ArcGIS, que obtenían como resultado los cambios de uso entre ambos periodos, a través de la siguiente función:

$$
\begin{aligned}
& \text { Usos }_{70} \bullet 1+\text { Usos }_{90} \bullet 1000=\text { Cambios }_{7090} \\
& \text { Usos }_{90} \bullet 1+\text { Usos }_{09} \cdot 1000=\text { Cambios }_{9009}
\end{aligned}
$$

Donde $\operatorname{Usos}_{n}$, es el ráster con los usos del suelo del periodo correspondiente, y Cambios ${ }_{n n}$ es el ráster resultante con los cambios producidos entre ambos periodos. Los valores de las categorías de Cambios $_{n n}$ que empiezan y 
terminan con la misma cifra corresponden a zonas en las que se mantiene el mismo uso del suelo, y por tanto sin cambios.

La incorporación de la información de los censos en la cartografía se realizó de dos maneras: Por una parte se georreferenció la posición de las especies de mayor interés (Athene noctua, Bubo bubo, Burhinus oedicnemus, Lanius excubitor, Otis tarda, Pterocles alchata, Pterocles orientalis, Pyrrhocorax pyrrhocorax, Tyto alba). Por otra parte se asignaron a cada uno de los usos del suelo el número de especies observadas en cada periodo en función de la bibliografía consultada y las anotaciones en campo de su ubicación, teniendo en cuenta al mismo tiempo las características de sus hábitats en la zona de estudio. De esta forma se espacializó la información del número de especies en función del hábitat que ocupan y estas en relación a los usos del suelo en la zona de estudio. Observando los cambios en estos usos, se pudo determinar cómo la distribución y la riqueza de las especies variaba en el tiempo.

\section{III.4. Análisis estadístico de los datos obtenidos mediante los censos}

Los datos de los censos recogidos durante las jornadas de campo fueron tratados estadísticamente en el programa SPSS para extraer tanto el número de especies en función de su fenología como para obtener tres índices de presencia que constataran la utilización del territorio por parte de las diferentes poblaciones de aves. Para obtener la diversidad de especies se utilizó el índice de Shannon (H').

donde:

$$
H^{\prime}=-\sum_{i=1}^{S} p_{i} \log _{2} p_{i}
$$

S es el número de especies

$\mathrm{p}_{\mathrm{i}}$ es la proporción de individuos de la especie i respecto al total de individuos

Los datos de Densidad (D) indicados en el estudio se expresan generalmente en:

$$
\mathrm{D}=\left(\mathrm{n}^{\mathrm{o}} \text { individuos }\right)(10 \text { has })
$$

donde $\mathrm{D}$ es la densidad de individuos por cada 10 hectáreas. Este índice es especialmente significativo en este caso, ya que refleja de manera más fiel la distribución de las especies recogidas en los taxiados realizados en campo. 
También se utilizó el Índice Kilométrico de Abundancia (IKA), que indica el número de individuos vistos por kilómetro recorrido, y la Riqueza Específica (número de especies presentes en una comunidad).

\section{IV) RESULTADOS}

\section{IV.1. Situación actual}

\section{a) Estructura actual de la comunidad aviar}

A través de los censos y taxiados realizados en el invierno y primavera de 2008-2009 en la zona de estudio se identificaron un total de 87 especies a través de un total de 3.171 observaciones, con un promedio de 11,6 especies y 53,1 ejemplares detectados por taxiado o censo, obteniendo una densidad específica de 7,1 especies/10 ha, con valores de diversidad de 3,28 según el índice de Shannon $(\mathrm{H})$.

Dentro de éste contexto general, la fenología de estas especies (FIGURA 1) muestra un reparto muy similar entre las de carácter estival (23\%) y las propiamente invernantes $(22 \%)$, siendo consideradas el $34 \%$ residentes en la zona y el $21 \%$ en paso migratorio. De todas ellas se ha podido constatar la nidificación en el área de estudio de un $17 \%$.

Figura 1. Distribución fenológica de la comunidad aviar

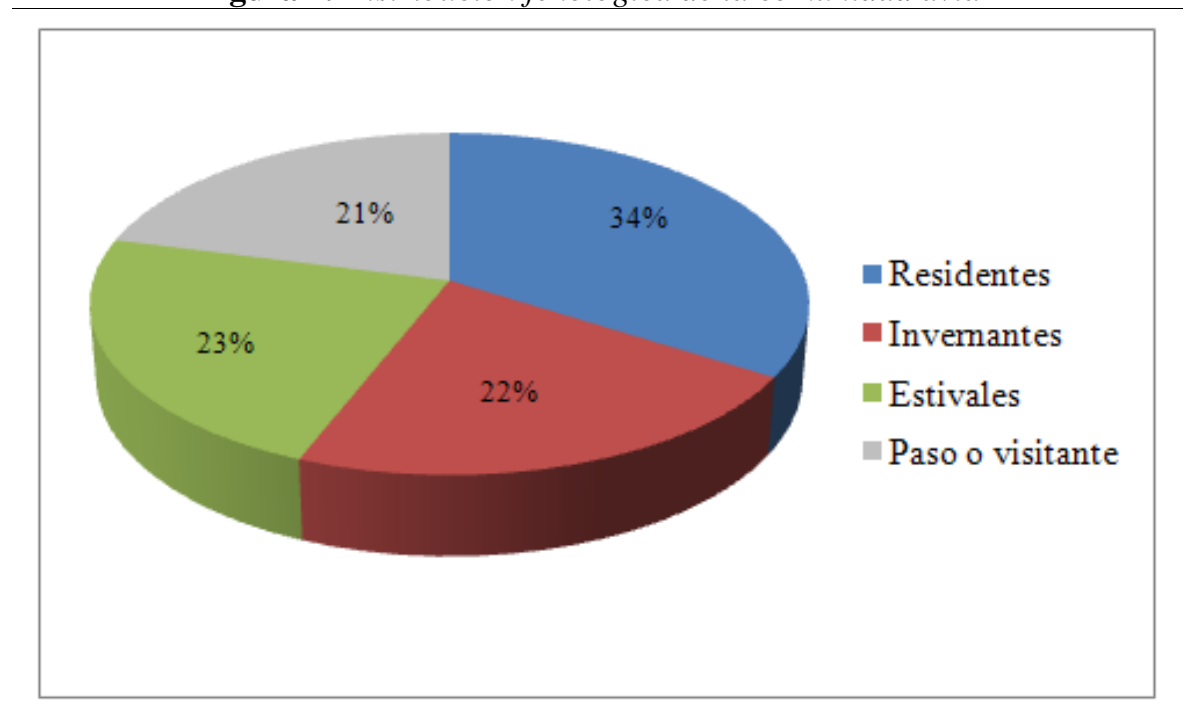

FUENTE: Elaboración propia

Para el conjunto de los meses en los que se desarrollaron los censos, enero se mostró como el mes en el que mayor número de especies (33) e indivi- 
duos (235) se detectaron, siendo el mes con valores más bajos abril con tan sólo 12 especies. Por otra parte los valores de mayor densidad específica se observaron durante los censos realizados en el mes de junio (10 especies/10 ha), con un índice kilométrico (IKA) de 31,5, destacándose claramente de los valores promedio del periodo de estudio $(7,1$ especies/10 ha. y un IKA de 20,1).

En cuanto a los datos obtenidos a través de los taxiados, la evolución mensual de los diferentes parámetros, que caracterizan la comunidad de aves de este sector del piedemonte ibérico (Figura 2), muestra variaciones significativas. Los valores de densidad (D) y del índice kilométrico (IKA) se muestran con un alto grado de correlación (Pearson) positiva $(\mathrm{r}=0,961)$ y la Diversidad (D) muestra los valores más bajos en el mes de abril al descender también durante este mes la riqueza específica, aunque presenta el segundo valor más alto en densidad, fruto de la dominancia originada por la presencia de unas pocas especies pero con un importante número de individuos.

Figura 2. Evolución de los parámetros de Densidad específica, IKA y Riqueza específica durante el periodo de realización de los taxiados

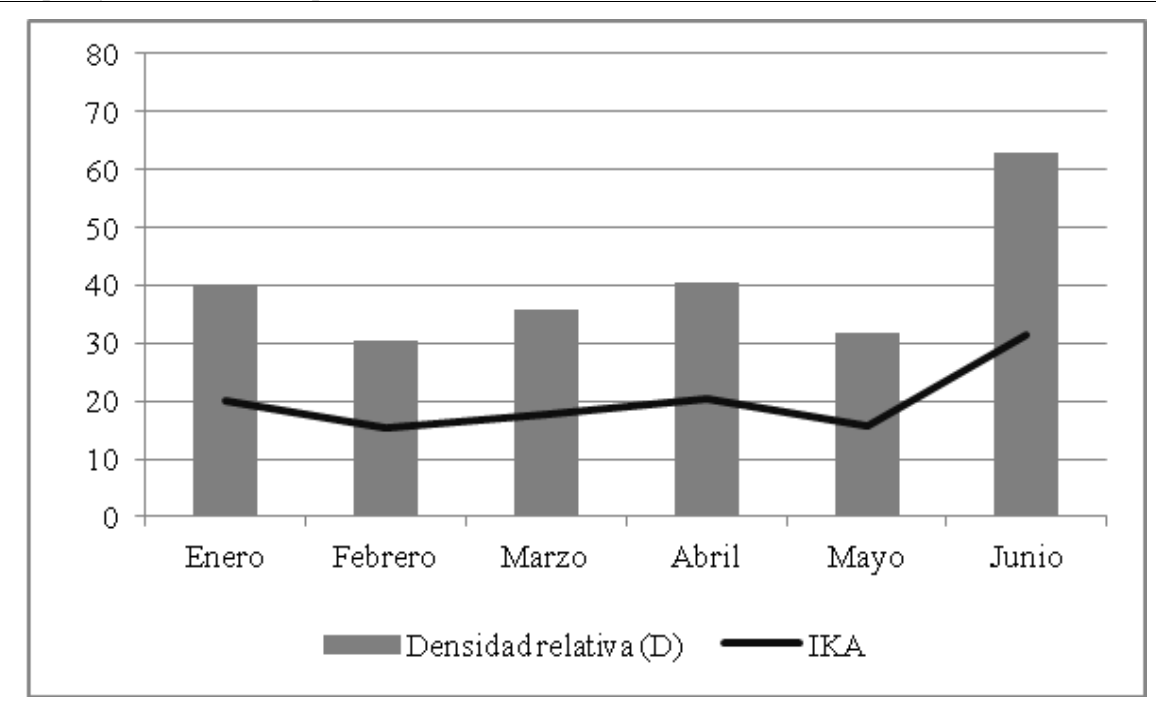

FUENTE: Elaboración propia

La diversidad sufre varios descensos durante el periodo de estudio. Febrero, junio, pero sobre todo abril, son los meses con los valores de diversidad más bajos, aunque presentan en los meses posteriores una pronta recuperación, al producirse una mayor equitatividad, especialmente en el mes de mayo. 
Figura 3. Evolución de los parámetros de Riqueza específica, Índice de Shannon y Equitatividad durante el periodo de realización de los taxiados

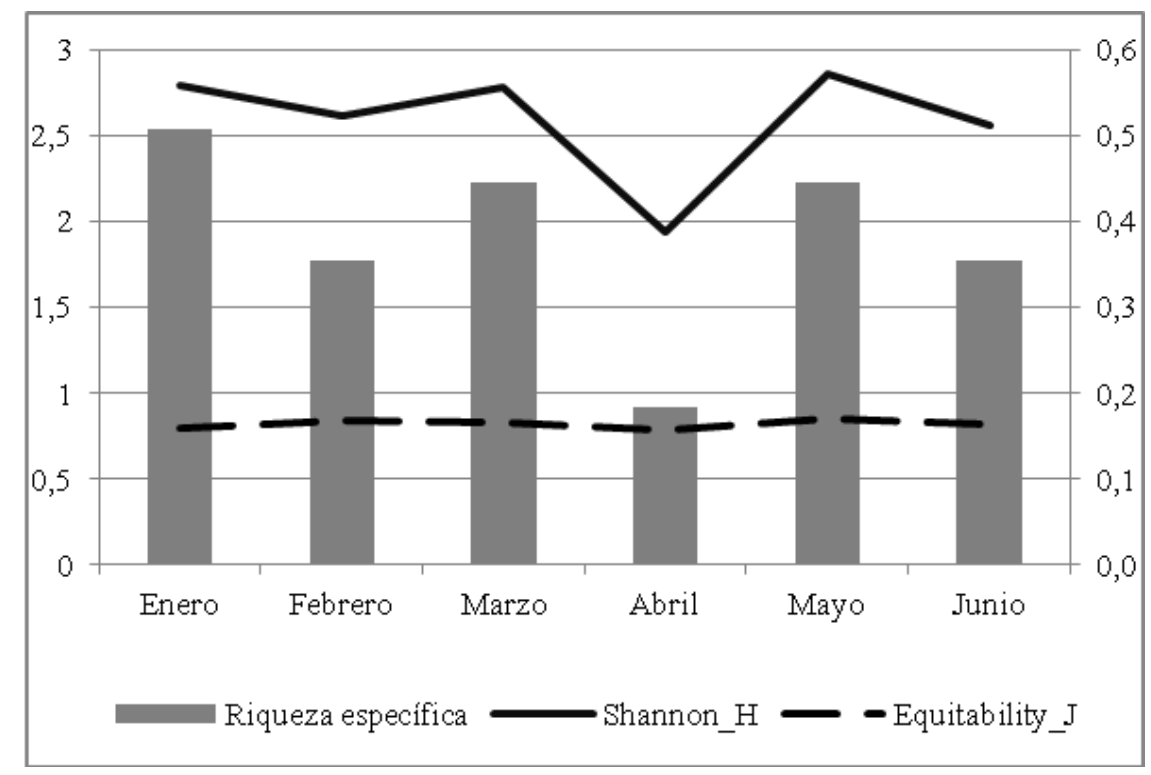

FUENTE: Elaboración propia

En el reparto mensual, el predominio corresponde a especies granívoras como Melanocorypha calandra (calandria común), Carduelis carduelis (jilguero) y Fringilla coelebs (pinzón vulgar), propio de ambientes con predominio de cultivos cerealistas de secano, presencia de barbechos y eriales, del mismo modo que el predominio de la Densidad (D) en los valores observados durante los meses invernales está inducido por la constancia observada en especies como Fringilla coelebs y Carduelis carduelis, cuyo comportamiento invernal está asociado a existencia de grandes bandos familiares.

Las especies con valores de densidad ( $\mathrm{n}^{\circ}$ individuos/10 ha) e índice kilométrico anual $\left(\mathrm{n}^{\circ}\right.$ individuos $\left./ \mathrm{km}\right)$ más elevados fueron Melanocorypha calandra, seguida de Carduelis carduelis y de Fringilla coelebs, mientras que el carácter más constante en cuanto a presencia se obtuvo para Alauda arvensis (alondra común) y de nuevo Melanocorypha calandra, datos que denotan el carácter estepario de la zona estudiada.

Si analizamos los datos de forma estacional desde el punto de vista de las especies, observamos como la mayor densidad invernal se obtiene para Carduelis carduelis y Fringilla coelebs, aunque la presencia constante corresponde a Pica pica (urraca), que se pudo observar en el 100\% de los taxiados, siendo frecuentes, aunque no constantes Turdus merula (mirlo común) y 
Fringilla coelebs. En la estación primaveral, los valores dominantes en densidad corresponden a Sturnus unicolor (estornino negro), seguida de Alauda arvensis y Merops apiaster (abejaruco común), siendo en este caso la especies más constante Alauda arvensis y Melanocorypha calandra, mostrándose como frecuentes Miliaria calandra (triguero) y Merops apiaster.

Figura 4. Reparto mensual del número de individuos y de especies observados

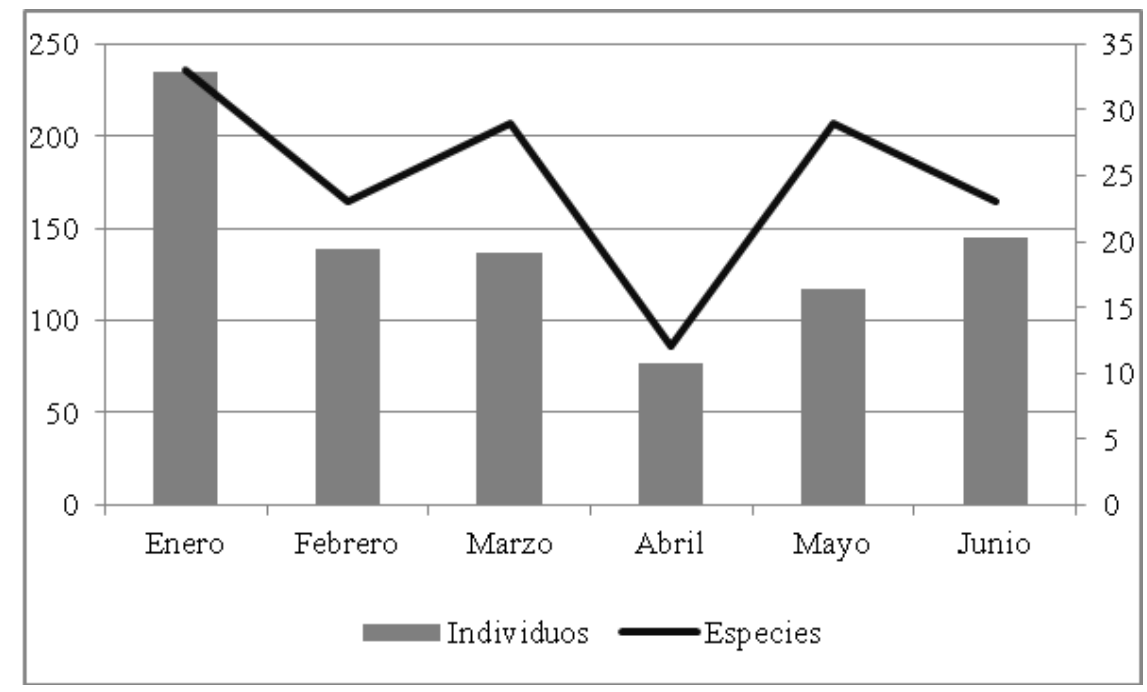

FUENTE: Elaboración propia

Por último dejar constancia de las observaciones realizadas en la zona de varias rapaces nocturnas como Bubo bubo (búho real), Tyto alba (lechuza común) y Athene noctua (mochuelo común), de los cuales se encontraron varios puntos con numerosas egagrópilas recientes y se escucharon sus cantos durante el periodo de celo, además de haberse levantado en varios transectos varios ejemplares de Athene noctua. Destacar también la observación de un ejemplar de macho de Otis tarda (avutarda) a principios del mes de junio sobre unos campos de rastrojo de cereal y cuya observación no volvió a repetirse en sucesivas visitas.

Dentro de la zona de estudio, destaca como se ha citado en capítulos anteriores, la presencia de una amplia lámina de agua denominada "Estanca de Borja", humedal artificial cuyo permiso de construcción data de 1328 por concesión del rey Alfonso (BRESSEL et AL., 1988; BORRÁS, 2008). En la actualidad, esta zona húmeda presenta un índice de diversidad de Shannon $(\mathrm{H})$ de 2,54 bits, pudiendo observarse en él un total de 45 especies, que ofrecieron como resultado una densidad (D) para el espacio ocupado por la Estanca 
entre la lámina de agua y sus orillas próximas (20 has.) de 47,1 aves/10 ha. y una densidad específica de 1,6 especies/10 ha., siendo mayor el número de individuos detectados durante la primavera (763) que durante el periodo invernal (556), por lo que los valores de densidad específica para la Estanca se situaron en cifras también alejadas, con un valor de densidad de 0,62 para la estación invernal y de 0,82 para la primavera.

Esta diferencia entre los dos periodos estacionales también se manifiesta en el número de especies detectadas, aunque los valores están mucho menos alejados entre ellos, ya que frente a las 16 especies observadas en primavera, se detectaron 13 durante el invierno, dando lugar a un promedio de especies detectadas para cada estación y día de censo se situara en valores similares (10,8 en invierno y 11,3 en primavera).

Las especies más constantes a lo largo del periodo censado fueron Circus aeruginosus (aguilucho lagunero), Anas platyrhynchos (ánade real) y Fulica atra (focha común), presentes en todos los censos, situación que se repite durante el periodo reproductor e invernal, aunque en este último se une como especie constante Phalacrocorax carbo (cormorán grande), que utiliza estos humedales de interior como lugar de invernada y a los que llega a través de los grandes cauces fluviales. Mientras que la especie que mayores densidades ha mostrado a lo largo del periodo censado es Anas platyrhynchos con 20,6 aves/20 ha., al año, seguida de lejos por otras acuáticas como Fulica atra y Phalacrocorax carbo, con valores de 4 aves/20 ha., situación que se mantiene para la estación invernal y primaveral.

\section{b) Usos del suelo}

En la actualidad, la mayor parte de la superficie del área de estudio está destinada a cultivos (MAPA 2), siendo los de regadío los que mayor extensión tienen $(37,63 \%)$. Éstos dominan la mitad oriental del área, mientras que los cultivos de secano $(35,78 \%)$, se ubican al Oeste, y más mezclados con manchas de matorral $(13,80 \%)$ y cultivos de viñedo $(3,56 \%)$. Las masas arbóreas $(5,92 \%)$ quedan reducidas al piedemonte de la Muela de Borja, aunque también aparecen de forma puntual en las riberas de los barrancos con agua semipermanente, y en las orlas de La Estanca de Borja, actuando como protección natural ante el viento permitiendo la presencia de una masa de carrizal importante en el interior de la balsa.

El continuo paso del ganado por las vías pecuarias, las zonas de pasto y, especialmente, las inmediaciones de los cursos de agua canalizados, favorecen la presencia y el desarrollo de las comunidades vegetales dominadas por 
la asociación Ruto angustifoliae-Brachypodium retusi, asociada a este tipo de ganadería extensiva.

\section{IV.2. Cambios para el periodo 1970-2009}

a) Análisis temporal de la comunidad aviar

En el área de estudio se ha constatado para el periodo 1978-2009 mediante bibliografía (ARAUJO y GARCÍA RUA, 1973; ARAUJO, 1978; PELAYO, 1978 y 1991; PURROY, 1997; SAMPIETRO et AL., 1998) y a través de las jornadas de campo descritas en la metodología, la presencia de un total de 101 especies.

Entre el trabajo realizado por Pelayo para la Estanca de Borja y su entorno próximo en 1978 y los taxiados y censos llevados a cabo en 2009, se observan varios cambios en cuanto al estatus de la población de aves de la zona de estudio.

En general, se constata un ligero incremento en el número de especies catalogadas como residentes, mientras que disminuyen las consideradas estivales y sobre todo las invernantes (FIGURA 5). Es este último grupo el que sufre un mayor descenso pasando de 27 especies con estatus invernante en 1978 a tan sólo 19 en 2009.

Figura 5. Cambios en el estatus del $n^{o}$ de especies de la comunidad aviar entre 1978 y 2009

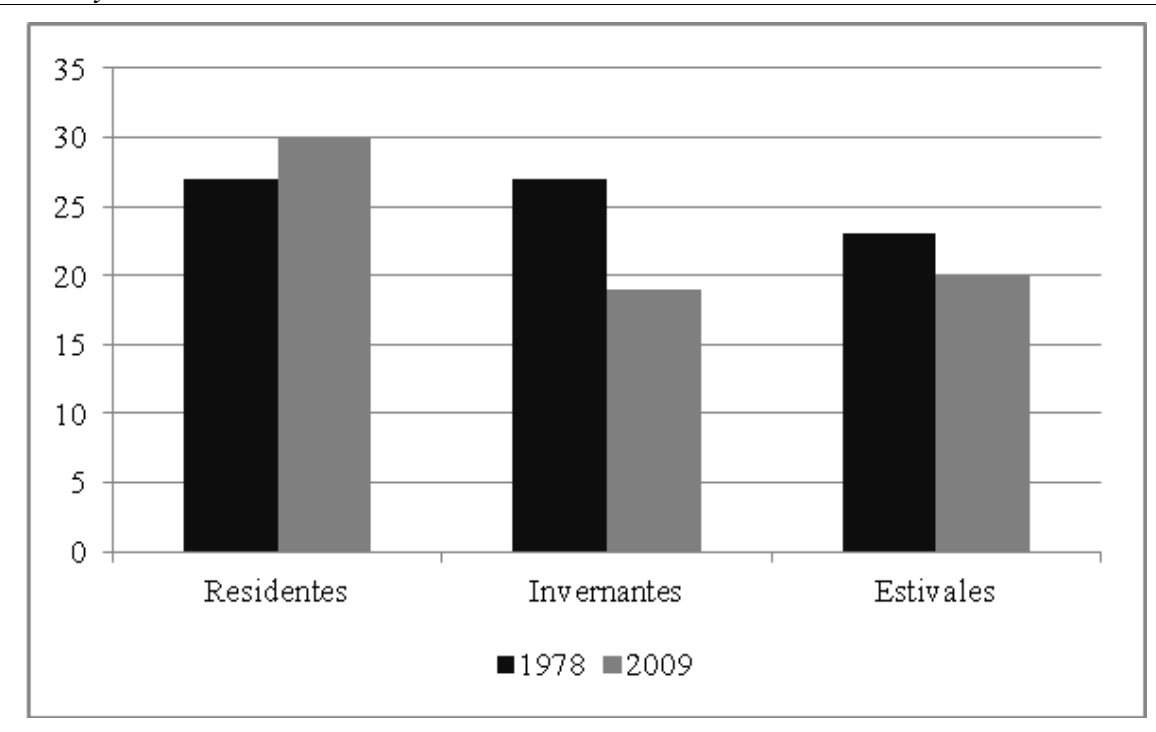

FUENTE: Elaboración propia 
En cuanto a las consideradas residentes, aunque se puede observar un ligero incremento en el cómputo global (FIGURA 6), en detalle se constata tan sólo el mantenimiento de 19 especies bajo este estatus de 1978 a 2009, habiendo desaparecido de la zona como residentes un total de 8 especies y apareciendo por el contrario 11 nuevas según los datos obtenidos en 2009.

En el caso de las estivales muestran una tendencia global contraria, ya que como se puede observar en la figura 6, se produce un descenso de 23 especies con este estatus a 20, dando lugar al mantenimiento bajo esa categoría para el periodo analizado tan sólo de 14 especies, abandonando este estatus 9 de las 23 detectadas en 1978 y apareciendo 7 nuevas en 2009. Por su parte el periodo invernal es el que mayor variabilidad muestra (FIGURA 6), ya que pasamos de tener un total de 27 especies consideradas invernantes en 1978 a tan sólo 19 en 2009, produciéndose la desaparición de 20 especies consideradas bajo este estatus a principio del periodo analizado y apareciendo 12 nuevas a finales, manteniéndose tan sólo 7 de ellas como invernantes para el total del intervalo de años.

Figura 6. Variación en el número de especies respecto al cómputo total del periodo 1978 y 2009 en relación con el estatus

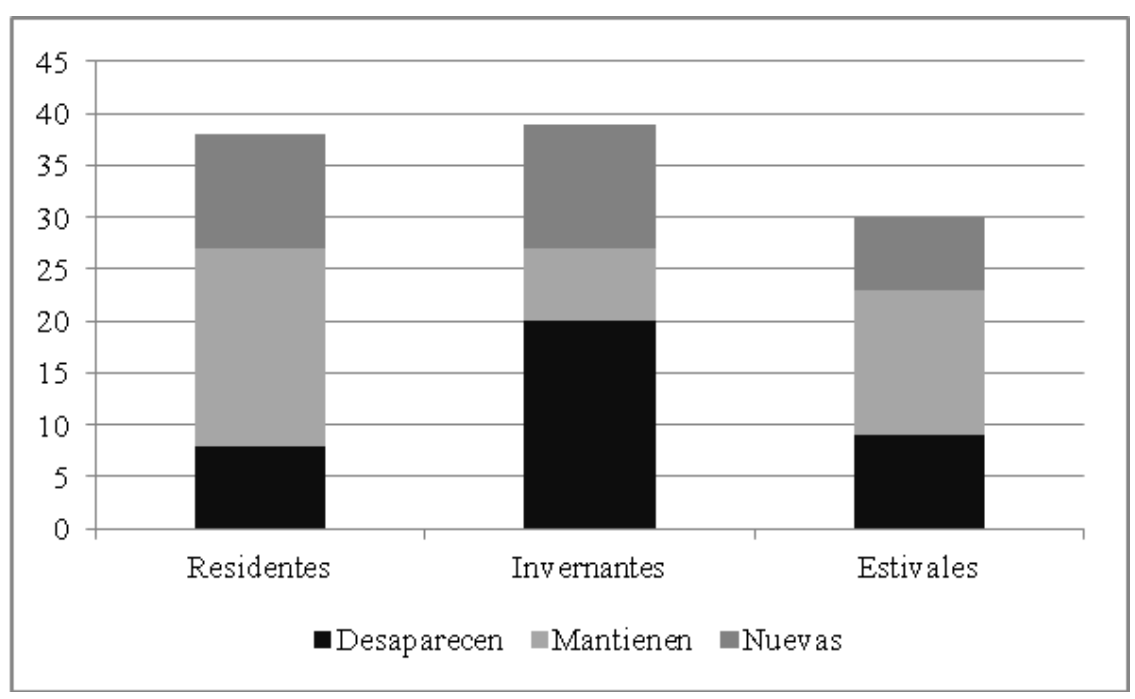

FUENTE: Elaboración propia

Si comparamos los datos de la Estanca con los disponibles para un total de 145 humedales censados en Aragón en el mismo periodo, podemos observar cómo la dinámica temporal en general es muy similar, en especial en cuanto al número de ejemplares observados a excepción de los años 2005 y 2006 (FIGURA 8), mientras que se observan algunas diferencias más notorias en el 
comportamiento de las especies (FIGURA 9). La tendencia creciente en el número de especies observadas en Aragón desde comienzos de la década de los 90, no se aprecia en la Estanca, donde tras el notable descenso en 1991, los valores permanecen estables en valores medios para el humedal, por el contrario la caída de los datos en 1998 hasta 2001 sí que tiene su reflejo en la Estanca, que alcanza los datos más bajos del periodo analizado y al contrario que en Aragón, que se observa una recuperación paulatina, hasta alcanzar los máximos valores en 2005, el humedal que nos ocupa, permanece en valores bajos hasta 2004 donde incrementa de forma importante los datos, manteniéndose en cifras similares durante el último quinquenio de la década de los 90, para en 2008-09 alcanzar su registro más elevado para el periodo que aquí se muestra.

Figura 7. Variación en el número de anátidas invernantes en la Estanca de Borja

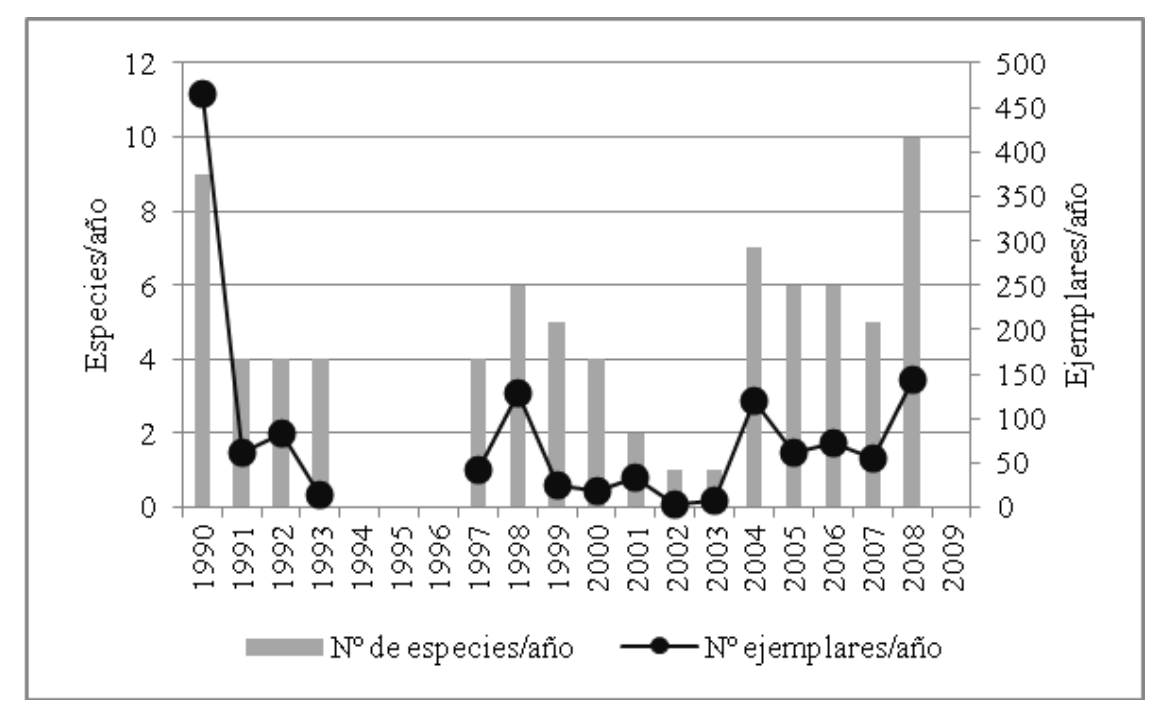

FUENTE: Datos 1990-2007 Gobierno de Aragón, 2008-09 propios

En esta evolución interanual, el peso de las especies en el aporte de individuos claramente es desigual. Así Anas platyrhynchos, con excepciones de algunos años como 1992-93 y 2002, ha sido censada con grupos más o menos numerosos, destacando 1990 (50 indiv.) y 2008-09 (80 indiv.), mientras que Fulica atra ha pasado de los 322 ejemplares censados en 1990 a desaparecer en un buen número de años como 1993, 2001, 2002, 2003 y 2007, mostrando cifras muy bajas en el resto, como la de 2008-09 con tan sólo 10 ejemplares, dinámica contraria a la mostrada por Phalacrocorax carbo cuya presencia ha ido incrementándose hasta alcanzar sus mayores cifras en el úl- 
timo censo. Estas dinámicas se corresponden con lo observado en el conjunto de humedales de Aragón, donde las tendencias de Anas platyrhynchos, Phalacrocorax carbo y Fulica atra son similares.

Figura 8. Comparación de la evolución en el número de ejemplares de aves invernantes en Aragón y en la Estaca de Borja

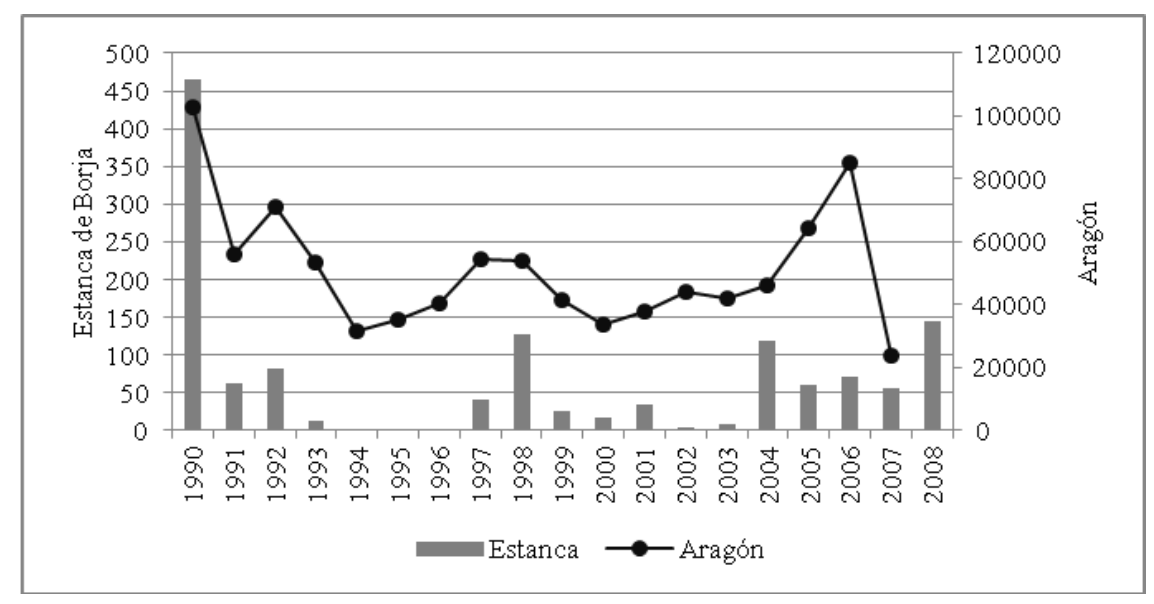

FUENTE: Datos 1990-2007 Gobierno de Aragón, 2008-09 propios

Figura 9. Comparación de la evolución en el número de especies de aves invernantes en Aragón y en la Estaca de Borja

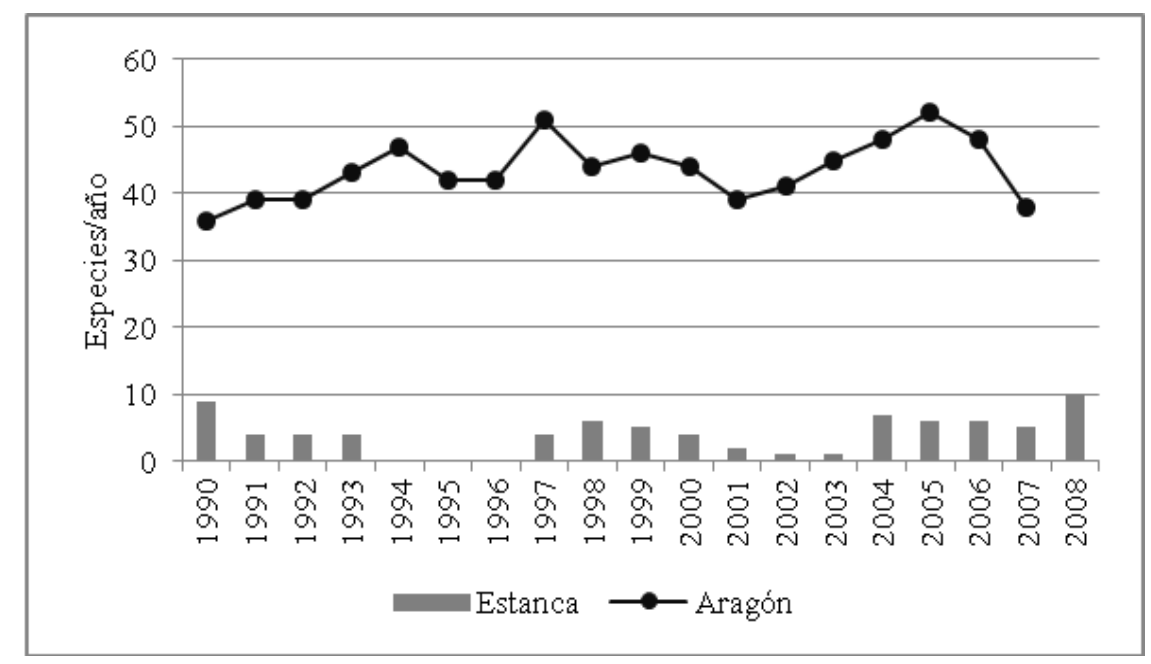

FUENTE: Datos 1990-2007 Gobierno de Aragón, 2008-09 propios 
Por último, destacar la constatación como reproductoras de algunas especies no detectadas en el trabajo realizado en 1988 y publicado tardíamente (Sampietro et $A L$., 1998). En este apartado son especialmente significativas Burhinus oedicnemus (alcaraván) y Melanocorypha calandra por su carácter estepario y Circus aeruginosus (aguilucho lagunero occidental) y Falco tinnunculus (cernicalo vulgar) dentro de las rapaces, todas citadas como presentes en diferentes periodos del año en los trabajos que cubre el periodo estudiado, pero sobre las que no existían citas como reproductores, habiéndose observado esta conducta en los censos de 2008-09.

\section{b) Cambios de uso del suelo}

El análisis de los cambios acaecidos en la zona de estudio entre 1970 y 2009, con dos periodos significativos de 20 años cada uno, 1970-1990 y 1990-2009 (MAPA 2), muestra diferencias significativas entre ambos que indican que, además de haber cambiado los usos del territorio en cada periodo, lo han hecho también entre ellos.

El mapa de cambios del periodo 1970-90 muestra un territorio más homogéneo en cuestión de usos del suelo. El regadío en su mayor parte se limitaba a zonas situadas al Norte del Canal de Lodosa, ya que al sur la disponibilidad de agua no era la misma que en la actualidad. Sin embargo, ya en los 90 se observa una reconversión de gran extensión de terreno de mosaico de cultivos-matorral, que representó un 9,5\% de todo el área estudiada, esto se debió en parte a la ampliación de zonas regables, y a las políticas de concentración parcelaria, muy activas desde 1974 (DE LA RIVA, 1990). Sin embargo, la diversificación de cultivos propició el incremento del mosaico de cultivos $(19,3 \%)$ en detrimento de zonas de vegetación natural dominadas principalmente por comunidades de matorral. Las masas arbóreas del piedemonte de La Muela de Borja se ampliaron ligeramente hacia las zonas llanas, lo que provocó una escasa reducción de las comunidades de matorral, que se contrarrestó con un incremento de éstas en puntos localizados del cuadrante noroeste, anteriormente ocupados por cultivos. Mención especial requiere el incremento de las zonas improductivas $(1,65 \%)$, debido principalmente a la construcción de la autopista AP-68 y al incremento de suelo urbano en las poblaciones de Mallén y Cortes.

Para el periodo 1990-2009 la cartografía muestra mayor detalle porque el mapa de usos del año 2009 se realizó a mayor resolución. Es significativo que la mayor parte de los cambios de uso se han dado en la mitad oeste del área de estudio, lo que significa que las comunidades de cultivos de secano y regadío se han mantenido intactas durante los últimos 20 años, y algunas de ellas (las colindantes con el Canal de Lodosa) desde los años 70. El mayor 
Mapa 2. Cambios de uso del suelo
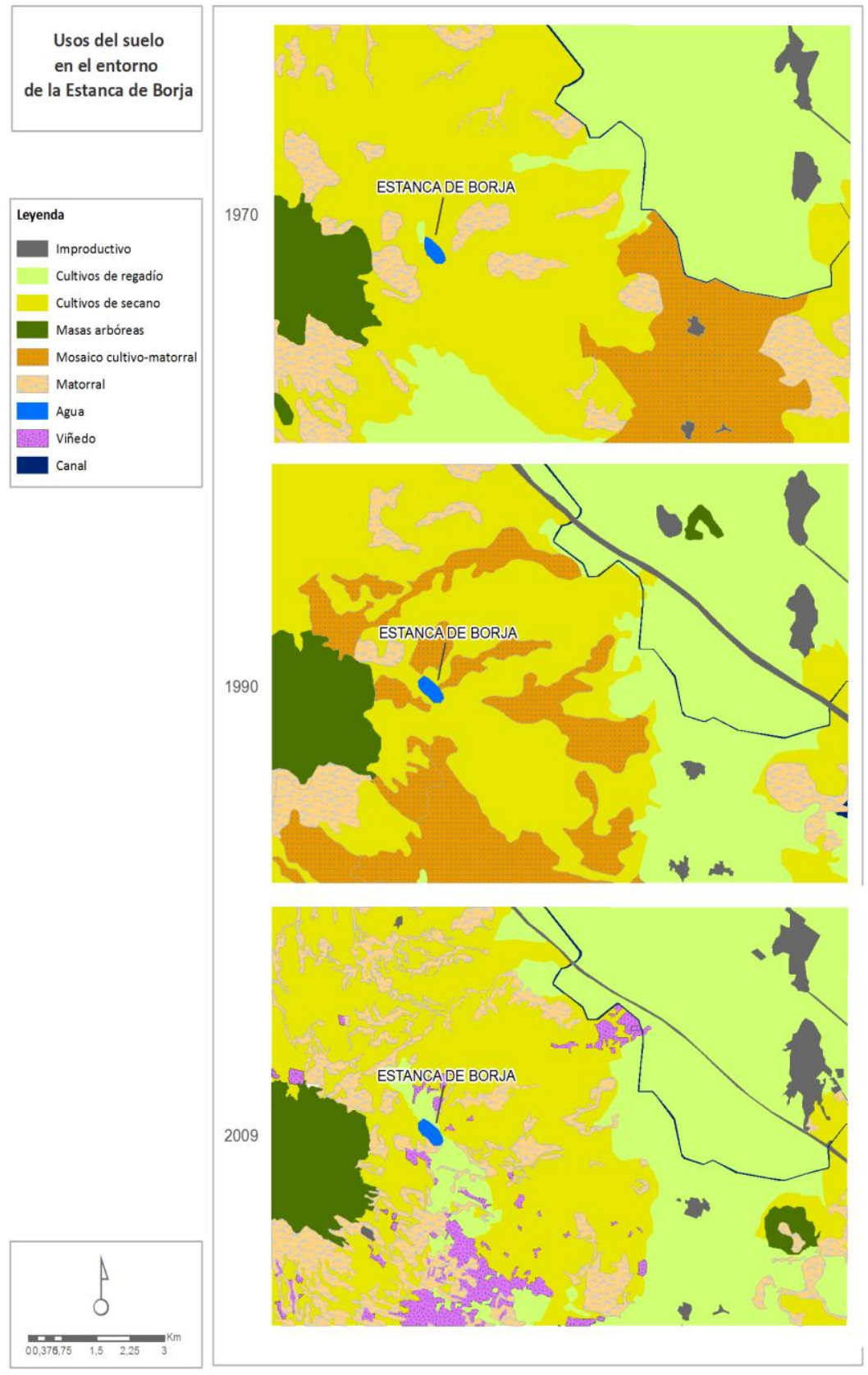

Polígonos. Revista de Geografía, 22 (2012); pp. 183-211 
cambio se ha dado en la conversión de diferentes categorías de suelo a cultivo de secano $(6,9 \%)$, que ha incrementado su extensión a costa de la disminución del mosaico de cultivos-matorral, que ya no aparece en el mapa de usos del suelo de 1990. Esto quiere decir que el mosaico se ha especializado, cultivando las zonas más accesibles, probablemente las más próximas a los campos colindantes en los que se cultivaba el mismo producto, y marginando al matorral en situaciones topográficas menos asequibles para el cultivo (el matorral obtuvo un incremento del 11,1\%).

La diversificación de cultivos continuó siendo predominante, y aparece por primera vez una extensión mediana de terreno dedicada al viñedo (incremento del 3,5\%). Esta unidad se cartografió como categoría independiente en el mapa de usos de 1990 porque había experimentado un aumento muy importante (en parte debido a la creación de la Denominación de Origen vitivinícola Campo de Borja, 1980), además, estructuralmente se trata de una comunidad similar al matorral pero de menor densidad, y antropizada, lo que puede modificar, a priori, las pautas de distribución de las aves.

Es reseñable el incremento de superficie denominada improductivo, que responde principalmente al aumento de suelo urbano en las dos poblaciones más importantes, como en el periodo anterior.

En resumen, en ambos periodos se observan grandes zonas de cambio de uso (un 60,94\% en el periodo 1970-1990, y un 68,28\% en el periodo 1990 2009 , respecto al total), pero en general el territorio muestra para el periodo analizado una dinámica de cambio relacionada con la expansión de los cultivos de regadío y la homogeneización de los cultivos de secano, disminuyendo el paisaje de mosaico tradicional en el que se intercalaban cultivos leñosos arbóreos y de cereal de secano, con matorrales y arbustos propios de la zona, diseñando con el paso del tiempo un escenario actual más homogéneo, continuo y simplificado, con la definición de varios espacios claros y dominantes, uno con una cubierta de cultivo de regadío y un segundo con una vocación de cultivos de secano por lo general herbáceos.

\section{c) Cambios en la distribución de los hábitats potenciales}

El establecimiento de una tipología de usos del suelo para el periodo analizado, y la asimilación de estos usos a los hábitats ocupados preferentemente por cada una de las aves detectadas en los tres periodos en los que se tienen datos, ha permitido establecer una cartografía de hábitats susceptibles de ser ocupados por las aves en función de sus características ecológicas en tres décadas diferentes. Con ello se ha obtenido la distribución del índice de riqueza 
específica para el territorio analizado en tres momentos diferentes del periodo 1970 y 2009 (MAPA 3).

\section{Mapa 3. Evolución del índice de riqueza específica según los hábitats}

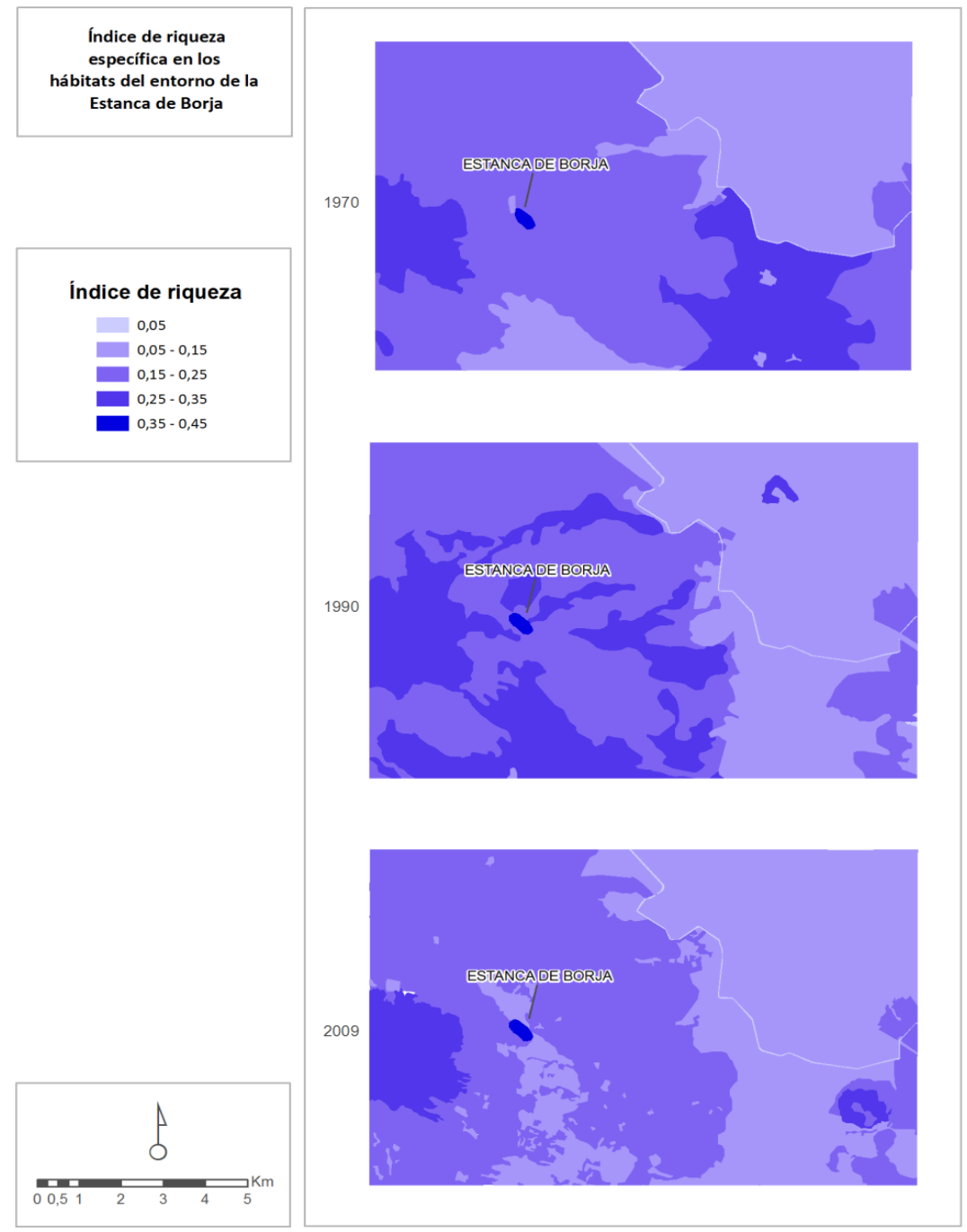

A grandes rasgos, se observa un empobrecimiento general del territorio, conforme avanza el periodo analizado, en cuanto al número de especies susceptibles de ocupar los diferentes hábitats delimitados. El importante avance de los espacios dedicados al regadío entre los 70 y los 90, en detrimento de los espacios mosaico de cultivos tradicionales y matorral y más tarde y más 
localizado entre los 90 y 2009, ha generado una importante pérdida de territorio susceptible de ser ocupado por un mayor número de especies, como se puede observar en la mitad este y en el entorno y al sur de la Estanca de Borja de los mapas que componen el MAPA 3.

El importante declive de la actividad agrícola en los años 80 en zonas de secano tradicional, llevó al incremento de los espacios mosaico de cultivo de secano y matorral xérico mediterráneo, esta situación se invierte a partir de las década de los 90, las políticas agrarias europeas incitan a la roturación de tierras mediante subvenciones, que ocasionan la ampliación de los cultivos de secano y una merma importante de los espacios ocupados por matorrales y pastizales típicos del valle del Ebro y que alcanzan importantes niveles de ocupación potencial por parte de las aves.

Por otro lado, la Estanca de Borja mantiene los valores más elevados del índice de riqueza específica en la zona de estudio, manteniéndose durante todo el periodo analizado en esta situación. Su especial condición de humedal dentro de un espacio semiárido y en el contexto de un pasillo migratorio importante, hacen que sea un enclave con un potencial elevado de ocupación por un buen número de especies, aunque como hemos visto en apartados anteriores, tampoco se ha librado de la disminución en el número de estas y sobre en el de sus efectivos poblacionales.

\section{DISCUSIÓN}

Nuestro trabajo muestra los cambios detectados en la población aviar en un territorio del piedemonte del Sistema Ibérico durante un periodo de 30 años, donde además se han producido modificaciones reseñables en el uso del mismo por parte del hombre. Estos plantean conclusiones que por un lado apuntan a los resultados obtenidos en trabajos que describen el declive de las poblaciones de aves en espacios agrícolas en relación con los cambios de uso y los sistemas productivos (CHAMBERLAIN Y FULLER, 2000; SIRIWARDENA et $A L$. 2000a, 2000b, 2001; STRIEN et $A L$., 2001; ROBINSON et $A L$., 2002) y por otro a aquellos que destacan la importancia del incremento de los cultivos herbáceos para especies de aves granívoras o la importancia del mantenimiento del pastoreo extensivo para otras (VERHULST et AL., 2004).

\section{V.1. Cambios de uso y especies}

Las dinámicas de cambios de uso descritas anteriormente, han dado lugar a la desaparición y/o disminución en la zona de estudio de los hábitats propicios para diversos paseriformes detectados a principios del periodo analizado (PELAYO, 1978). Esta ausencia de observaciones del grupo de escribanos o papamoscas, parece estar relacionada con la disminución de los paisajes mo- 
saico, de los que son habituales y que facilitan la movilidad de estas aves (HERRANDO y BROTONS, 2002), contribuyendo a la disminución de la riqueza específica a nivel espacial.

Por el contrario, la mayor presencia de superficies dedicadas al cultivo cerealista de secano, con la consiguiente aparición de rastrojos y barbechos, puede haber contribuido al asentamiento como residentes de Pterocles alchata, P. orientalis y Alauda arvensis, aves muy ligadas durante todo el ciclo anual a los barbechos y rastrojos en especial en el Valle del Ebro (SUÁREZ et $A L$., 2006), así como la selección de estos espacios por parte de Burhinus oedicnemus como lugares de reproducción, aunque estas se han concentrado en la mitad oriental de la zona de estudio, fuera de las zonas con dominio de los cultivos de regadío. En este caso, estas incorporaciones suponen una menor aportación desde el punto de vista específico, así como en el número de individuos para el total de la comunidad del territorio estudiado, por lo que en general la zona ha visto disminuir espacialmente el reparto de la riqueza específica.

Del mismo modo, los cambios observados en el entorno próximo de la Estanca, han contribuido a una pérdida de hábitat para el grupo de las aves limícolas, ya que su presencia invernante o en paso se ha visto reducida drásticamente, pudiendo asociarse este declive a una reducción de espacios en el margen de la Estanca seleccionados por este grupo de aves, fundamentados en la colonización por parte de comunidades de hidrófitos de las orillas y márgenes de la Estanca o un incremento de las molestias (PÉREZ-HURTADO, 1997; OLTRA y GÓMEZ-SERRANO, 1997), por el incremento de la actividad antrópica en la zona, ligada a actividades de ocio como la pesca deportiva, u otras de tiempo libre como rutas en bicicleta de montaña y vehículos a motor, entre otras.

\section{V.2. Cambios de uso poblacionales y del estatus}

El descenso del número total de especies y ejemplares con estatus invernante en la zona de estudio, está relacionado con la dinámica observada para la comunidad de anátidas, zancudas y limícolas de la Estanca de Borja, que parecen responder en sus variaciones a parámetros de mayor escala (nacional o de regiones biogeográficas), ya que como apuntan diversos autores (KUSHLAN, 1993; GREEN y FIGUEROLA, 2003), no es conveniente suponer que un cambio en este grupo de aves indica algún cambio en las condiciones del humedal estudiado.

Así, para las anátidas, se conocen declives poblacionales en el Paleártico Occidental, especialmente significativos en el Mediterráneo occidental y 
oriental, en relación con la pérdida de humedales (DELANY et AL. 1999), siendo este el principal problema de conservación para este grupo de aves. Esta parece ser la razón de la disminución del número de ejemplares en las concentraciones de anátidas en la Estanca de Borja, ya que sus patrones de evolución son similares a los observados para el resto del territorio aragonés, teniendo en cuenta por otra parte que las características de tamaño y situación aislada del humedal no lo hacen especialmente propicio para albergar grandes concentraciones y sí ser más apto para la presencia de aves más abundantes y ubicuas en general (ELMBERG et $A L$., 1994), como hemos venido observando.

Por otra parte, el pronunciado descenso de la diversidad, especialmente a finales del periodo invernal, resulta evidente y al mismo tiempo atribuible a la disminución del número de efectivos en la población de aves invernantes, que inician los movimientos migratorios prenupciales y que en los meses invernales la comunidad de aves se incrementa con especies que tienen un gran peso cuantitativo en cuanto a número de ejemplares en esa estación del año.

Algunos de estos cambios resultan significativos, como los observados para especies caracterizadas como visitantes ocasionales de la zona en 1978 y que en 2009 pueden ser consideradas como residentes, es el caso de Pterocles orientalis (ganga ortega) asociado a la mayor presencia de barbechos, rastrojos y cereal de secano (MARTínEZ y DE JUANA, 1996; SUÁREZ et AL., 1999 y 2006; CAMPOS, 2004; MARTÍNEZ, 2005; MARTín et AL., 2010) y Columba palumbus (paloma torcaz), cuya presencia se ve favorecida por las masas forestales de Pinus halepensis del entorno o el de Podiceps cristatus (somormujo lavanco), citado como estival y que ha podido ser observado con carácter residente en 2009, favorecido por la estabilidad del nivel de las aguas de la Estanca, el incremento de la cubierta vegetal de las orillas y su capacidad de ocupar humedales artificiales (MARTí y DEL MORAL, 2003). Por el contrario, Picus viridis (pito real), conocido como residente en 1978, tan sólo ha sido observado como no reproductor durante el periodo estival en el último año, pudiendo tratarse de ejemplares que utilizan la zona durante sus movimientos locales y dispersivos al considerarse la población española como sedentaria (MARTí y DEL MORAL, 2003), por lo que entendemos como probable que la especie haya desplazado su lugar como residente a territorios limítrofes con mejores condiciones.

Más relevante es el caso de Alauda arvensis, que pasa de ser considerada en 1978 como invernante a constatarse su presencia como residente todo el año en la zona en 2009. A esta situación puede contribuir las condiciones actuales fruto de los cambios de uso del suelo en la zona de estudio, adquirien- 
do características propias de las zonas representativas de su óptimo poblacional, con usos de cereal de secano por encima de $700 \mathrm{~m}$ (SAMPIETRO et $A L ., 1998)$ y el mantenimiento de linderos y áreas con vegetación natural dedicada al pastoreo (MARTí y DEL MORAL, 2003).

Los censos de aves invernantes en la Estanca de Borja entre 1990 y 2009 también muestran cambios significativos. En la evolución total del humedal, se observa como en los 16 años censados existe una variación interanual importante tanto en el número de individuos como en el de especies. Destaca el importante descenso de ambas cifras en 1991 respecto a 1990, así como algunos años especialmente pobres tanto en el número de especies e individuos (2001, 2002 y 2003), y el descenso del número de ejemplares observado en 1993, que no sigue la misma tendencia en el número de especies, que permanece en cifras similares a los años anteriores. Estas variaciones interanuales deben ser atribuidas a fluctuaciones demográficas o situaciones meteorológicas (BERTHOLD y TERRILL, 1991; AMAT y FERRER, 1988), y no a la permanencia de la lámina de agua en la cubeta, ya que en la Estanca, esta es constante a lo largo del año y del periodo analizado, prestando especial importancia a los años en los que acontecen olas de frío en Europa como responsables de concentraciones de un mayor número de individuos (FORTUNA, 2003).

\section{V.3. Ausencias, especies nuevas y aumento de presencia}

Entre las especies no citadas en 1978, y que son observadas como residentes en la actualidad, destaca Pterocles alchata (ganga ibérica), estando relacionada su presencia con sus preferencias de hábitats, entre los que se encuentran los cultivos de plantas arvenses con presencia de barbechos, evitando los campos de cereal cuando éste ya está crecido (MARTínEZ y DE JUANA, 1996; SUÁrEZ et AL., 1997; SUÁREZ et AL., 1999; CAMPOS, 2004; MARTÍNEZ, 2005; SUÁREZ et $A L$., 2006; MARTÍN et $A L ., 2010$ ) y cuya superficie como se ha descrito en los resultados del análisis de cambios de uso, se ha incrementado en la zona de estudio en detrimento de los cultivos de viñedo, no pudiendo constatar si se trata de poblaciones desplazadas de territorios próximos o nuevas.

Se constata el asentamiento de especies de ámbito forestal como Garrulus glandarius (arrendajo), que obedece sin duda alguna a la madurez alcanzada por los bosques (AlONSO, 2006), en este caso repoblaciones de Pinus halepensis realizadas en los años 70 en el límite norte de la zona de estudio, y que durante los trabajos de Pelayo no ofrecían condiciones como hábitat para aves forestales. Los individuos observados pueden ser ejemplares en desplazamiento que aprovechan los campos de almendros y la vegetación de ribera 
(SALVADOR, 2009) como corredores entre las masas forestales situadas en el entorno.

Destaca la presencia frecuente como invernante de Ardea cinerea (garza real), en relación con el aumento de su población en el valle del Ebro (MARTí y DEL MORAL, 2003) y la llegada de ejemplares europeos invernantes (DíAZ et AL., 1996) al igual que ocurre con Ardea purpurea (garza imperial) durante el paso migratorio. Del mismo modo, Larus michahellis (gaviota patiamarilla) ha visto incrementado el número de observaciones, en consonancia con el proceso expansivo observado en su área de distribución occidental (CRAMPS y SimMOnS, 1982; CARRERA, 1997), al igual que Tadorna tadorna (tarro blanco) para el que se viene constatando una expansión hacia el sur de su área de invernada (ROBLEDANO y CALVO, 1989).

Sin embargo, el mayor número de cambios se observa en las anátidas que dejan de ser observadas en la zona de estudio durante el periodo invernal: Anas strepera (ánade friso), Anas penelope (silbón europeo), Anas querquedula (cerceta carretona), Anas clypeata (cuchara común) y Aythya fuligula (porrón moñudo). En este caso, es difícil establecer la causa de estas ausencias tan sólo teniendo en cuenta factores locales del humedal (KUSHLAN, 1993; GREEN y FIGUEROLA, 2003), pero resulta significativo que ante la ausencia de fluctuación o disminución de la lámina de agua de La Estanca de Borja, por lo que no existe en La Estanca merma en la capacidad de acogida (BOERTMAN y RIEGET, 2005), sí que es importante en el periodo de estudio el incremento de otros factores que contribuyen a la alteración del hábitat de estas especies como las molestias humanas (ERWIN, 1996), en este caso derivadas de la actividad cinegética y de ocio y la disminución de las zonas de aguas someras, ya de por sí no muy extensas en La Estanca, factor que también parece estar en consonancia con la disminución del número de especies y ejemplares de zancudas y limícolas en invierno y periodos de paso como: Gallinago gallinago (agachadiza común), Limosa limosa (aguja colinegra), Tringa glareola (andarríos bastardo), Tringa nebularia (archibebe claro), Tringa totanus (archibebe común), Tringa erythropus (archibebe oscuro), Grus grus (grulla común).

Por último, destacar la ausencia de observaciones de algunas rapaces como: Aquila pennata (aguililla calzada), Circus pygargus (aguilucho cenizo) y Circaetus gallicus (culebrera europea), aunque dentro de este grupo la que resulta especialmente significativa por su ausencia es Neophron percnopterus (alimoche común), reflejando la tendencia poblacional regresiva observada a nivel peninsular en los últimos años (PEREA et AL., 1990, DEL MORAL y MARTí, 2002), especialmente significativa en el valle del Ebro 
(TELLA et AL. 2000) y en concreto en la zona de estudio donde se tenía constancia de su presencia como reproductor (SAMPIETRO et AL., 1998).

\section{BIBLIOGRAFÍA}

AlCÁntarA, M. y GAJón, A. (2004): «Restauración de edificios agrícolas como hábitat de nidificación. Programa LIFE para la conservación del hábitat de nidificación de Cernícalo Primilla». Póster en el VI Congreso Nacional sobre el Cernícalo Primilla. Zaragoza, 2004.

AlONSO, C.L. (2006): «Arrendajo - Garrulus glandarius». En Enciclopedia Virtual de los Vertebrados Españoles. CARrascal, L.M., Salvador, A. (Eds.). Museo Nacional de Ciencias Naturales, Madrid. http://www.vertebradosibericos.org/

AMAT, J.A. y FERRER, X (1988): «Respuestas de los patos invernantes en España a diferentes condiciones ambientales». Ardeola, 35 (1) 59-70.

Araujo, J. (1978): «Censo Español de aves acuáticas de enero de 1975». Ardeola, 24: 121-205. Seo/BirdLife. Madrid.

Araujo, J. y GarcíA RuA, A.E. (1973): «El censo de español de aves acuáticas de enero de 1973». Bol. Est. C. Ecología, no 4, 11-39. Madrid.

Berthold, P. y TERRILl, S. B. (1991): «Recent advances in studies of bird migration». Annu. Rev. Ecol. Syst., 22:357-378.

BOERTMAN, D y RIDGET, F. (2005): «Effects of Changing Water Levels on Number of Staging Dabbling Ducks in a Danish Wetland». Waterbirds, 29 (1): 1-8.

Borras GuAliz, G.M., (2008): Arte mudéjar aragonés. Tomo I. Ed. Prames. Zaragoza.

Bressel, C.; LombA, C. y MARCO, R. (1988): Borja. Arquitectura y evolución urbana. Delegación del Colegio Oficial de Arquitectos de Aragón. Zaragoza

CAMPOS, B. (2004): «Abundancia, distribución y selección de hábitat de la población reproductora de ganga ibérica Pterocles alchata en la provincia de Albacete». En: II Jornadas sobre el medio natural albacetense. Diputación de Albacete, Albacete, pp. 499-507.

CArrera, E. (1997): «Gaviota Patiamarilla». En Purroy, F. (Cood). Atlas de las aves de España (1975 - 1995). Seo/ BirdLife. Linx Ediciones, 583 pp.

Chamberlain, D. E. y Fuller, R. J. (2000): «Local extinctions and changes in species richness of lowland farmland birds in England and Wales in relation to recent changes in agricultural land-use» Agriculture, Ecosystems and Environment, 78: $1-17$.

Cramp, S. y Simmons, K.E.L. Eds. (1982): The Birds of the Western Paleartic. Vol. III. Oxford University Press. Oxford, 913 p.

De la Riva, J. (1990): «La Política de Concentración parcelaria en Aragón». Revista de Estudios Agrosociales, 151, págs. 191-236.

Del Moral, J.C. y Martí, R. Eds. (2002): El Alimoche Común en España y Portugal (I Censo coordinado). Año 2000. Monografía n ${ }^{\circ}$ 8. SEO/BirdLife. Madrid.

Delany, S.; Reyes, C.; Hubert, E.; Pihl, S.; Rees, E.; HaAnstra, L. y VAN STRIEN, A. (1999): Results from the International Waterbird Census in the Western Paleartic and Southwest Asia 1995 and 1996. Wetlands International Publication, 54. Wageningen. 
DíAZ, M., Asensio, B. y TelleríA, J.L. (1996): Aves ibéricas I. No paseriformes. J.M. Reyero Editor. Madrid.

ElmberG, J.; Nummi, P.; PÖYSÄ, H. y SJÖBERG, K. (1994): «Relationships between species number, lake size and resource diversity in assemblages of breeding waterfowl». Journal of Biogeography, 21: 75-84.

ERWIN, R.M. (1996): «Dependence of Waterbirds and Shorebirds on Shallow-Water Habitats in the Mid-Atlantic Coastal Region: An Ecological Profile and Management Recommendations» Estuaries. Vol. 19 (2), Part A.

ForTunA, M.A. (2003): «Dependencia hídrica de la comunidad ornítica acuática de la laguna de Manjavacas: la importancia de la desecación estival». Oxyura, 11(1) 85-98.

Furnes, R.W., y GREENwOOD, J.J.D. Eds. (1993): Birds and Monitors of Environmental Change. Chapman \& Hall, London.

Gajón, A., Serrano, D., Ursúa, E., Tella, J.L. (2004): «Conservación de aves nidificantes en edificios Agro-pastorales de las ZEPAs de Monegros». Póster en el VI Congreso Nacional sobre el Cernícalo Primilla. Zaragoza, 2004.

Green, A.J. y FiguerolA, J. (2003): «Aves acuáticas como bioindicadoras en los humedales» En, PARACUELLOS (Coord.): Ecología, manejo y conservación de los humedales. Instituto de Estudios Almerienses.

Herrando y Brotons (2002): Forest bird diversity in Mediterranean areas affected by wildfires: a multi-scale approach. Ecography 25: 161-172.

JARVINEN, O. y VAISANEN, R. (1975): «Estimating relative densities of breeding birds by the line transect method» Oikos 26: 316-322.

KUSHLAN, J. (1993): «Waterbirds as indicators of wetland change: are they a valuable tool?» En: Waterfowl and wetland convservation in the 1990s - a global perspective. Proc. IWRB Symp., St. Petersburg Beach, pp. 48-55. IWRB Special Publication, 26. IWRB. Florida.

LASANTA, R.; ViCENTE-SERRANO, S. y CUADRAT, J.M. (2005): «Mountain mediterranean landscape evolution caused by the abandonment of traditional primary activities: a study of the Spain Central Pyrenees» Applied Geography, 25: 47-65.

MARTí, R. y Del Moral, J.C. Eds. (2003): Atlas de las aves reproductoras de España. Madrid: Dirección General Conservación de la Naturaleza-SEO/BirdLife.

Martín, C. A., Casas, F., Mougeot, F., García, J. T., ViÑuela, J. (2010): «Seasonal variations in habitat preferences of the pin-tailed sandgrouse in agrarian pseudo-steppes» Ardeola, 57: 191- 198.

MARTíNEZ, C. (2005): Distribución, abundancia, requerimientos de hábitat y conservación de aves esteparias de interés especial en Castilla-La Mancha. Consejo Superior de Investigaciones Científicas, Madrid.

MARTÍNEZ, C., DE JUANA, E. (1996): «Breeding bird communities of cereal crops in Spain: Habitat requirements».. En: FERnÁNDEZ GuTIÉRREZ, J., SANZ-ZUASTI, J. (Eds.): Conservación de las aves esteparias y su hábitat. Junta de Castilla y León, Valladolid, pp. 99-106.

Oltra, C. y GómEZ-SERrAnO, M.A. (1997): «Amenazas humanas sobre las poblaciones de limícolas en ecosistemas litorales». En: BARBOSA, A. (Ed.): Las aves limícolas en España. Organismo Autónomo de Parques Nacionales, pp. 201-212. 
PAdoA-Schioppa, E., BAietTo, M., Massa, R. y BotToni, L. (2006) «Bird communities as bioindicators: The focal species concept in agricultural landscapes». Ecological Indicators 6: 83-93.

Pelayo ZueCo, E. (1978): La Estanca de Borja: sus aves. Cuadernos de Estudios Borjanos II. Centro de Estudios Borjanos. Institución "Fernando El Católico". Borja.

Pelayo Zueco, E. (1991): Aves nidificantes de la Comarca del Moncayo y Campo de Borja. Centro de Estudios Borjanos. Institución "Fernando El Católico". Borja.

Perea, J.L., Morales, M., Velasco, J. (1990): El Alimoche Neophron percnopterus en España. ICONA, Col Tecnica. Madrid.

PÉreZ-Hurtado, A., (1997): «Efecto de actividades humanas en las poblaciones invernantes de Limícolas». En: BARBOSA, A. (Ed.): Las aves limícolas en Espa$\tilde{n} a$, Organismo Autónomo de Parques Nacionales, pp. 201-212.

PURROY, F.J. -Coord.- (1997): Atlas de las aves de España (1975-1995). Lynx Editions. Barcelona.

ROBINSON, R.A., WILSON, J.D. y CRICK, H.Q.P. (2002): «The importance of arable habitat farmland birds in grassland landscapes» Journal of Applied Ecology, 38, 1059-1069.

Robledano, F. y CALvo J.F. (1989): «La expansión del Tarro blanco, Tadorna tadorna (L.) como reproductor en España». Ardeola, 36. 91-95.

SALVADOR, E. (Ed.) (2009): Enciclopedia virtual de los vertebrados españoles. Museo Nacional de Ciencias Naturales. CSIC.

Sampietro, F.J., Pelayo, E., Hernández, F., Cabrera, M. y Guiral, J. Eds. (1998): Aves de Aragón. Atlas de especies nidificantes. Diputación General de Aragón e IberCaja. Zaragoza.

SANTOS MARTínEZ, T. (2004): «Aves y paisaje: respuesta de las comunidades de aves a la pérdida y fragmentación del hábitat». En: TELLERÍA, J.L. y BERNIS, F. La ornitología hoy: homenaje al profesor Francisco Bernis Madrazo. Complutense. Madrid.

SANTOS, T. y TelleríA, J.L (2006): «Pérdida y fragmentación del hábitat: efecto sobre la conservación de las especies». Ecosistemas 15 (2), 3-12. Madrid.

Siriwardena, G. M., BAillie, S. R., Crick, H. Q. P. y Wilson, J. D. (2000a): «The importance of variation in the breeding performance of seed-eating birds in determining their populations trends on farmland», Journal of Applied Ecology, 37: 128-148.

Siriwardena, G. M., BAillie, S. R., CRick, H. Q. P. y Wilson, J. D. (2000b): «Agricultural habitat-type and the breeding performance of granivorous farmland birds in Britain». Bird Study, 47: 66-81.

Siriwardena, G. M., Baillie, S. R., Crick, H. Q. P. y Wilson, J. D. (2001): «Changes in agricultural land-use and breeding performance of some granivorous farmland passerines in Britain». Agriculture, Ecosystems and Environment 84: 191-206.

Strien, A. J. VAn, PAnnekoeK, J. y Gibbons, D. W. (2001): «Indexing European bird population trends using results of national monitoring schemes: a trial of a new method» Bird Study, 48: 200-213 
Suárez, F., Herranz, J., Martínez, C., Manrique, J., Astrain, C., Echeverria, A., Curcó, A., EstradA, J., YANES, M. (1999): «Utilización y selección de hábitat de las gangas ibérica y ortega en la Península Ibérica». En: HerRanz, J., SuÁrez, F. (Eds.): La Ganga Ibérica (Pterocles alchata) y la Ganga Ortega (Pterocles orientalis) en España: Distribución, abundancia, biología y conservación. Ministerio de Medio Ambiente. Organismo Autónomo Parques Nacionales, Madrid, pp. 127-156

Suarez, F., Hervás, I., Herranz, J. y Del Moral, J.C. (2006): La ganga ibérica y la ganga ortega en España: población en 2005 y método de censo. SEO/BirdLife. Madrid.

SuÁrez, F., Martínez, C., Herranz, J., Yanes, M. (1997): «Conservation status and farmland requirements of Pin-tailed Sandgrouse Pterocles alchata and Blackbellied Sandgrouse Pterocles orientalis in Spain». Biol. Conserv., 82: 73-80.

Tella, J.L., Grande, J.M., SERRAno, D. y DonaZAR, J.A. (2000): Monitorización de la población de Alimoche (Neophron percnopterus L.) en el valle medio del Ebro. Gobierno de Aragón. Informe inédito.

TELLERÍA, J.L. (1978): «Introducción a los métodos de estudio de las comunidades nidificantes» Ardeola 24. 19-65.

TELLERÍA, J.L. (1986): Manual de censo de los vertebrados terrestres. Ed. Raíces.

TELlERÍA, J.L., y GARZA, V. (1983): «Methodological features in the study of a Mediterranean forest bird community» En: Censos de aves en el Mediterráneo, F.J. PURROY (ed.) Universidad de León. León, pp. 89-92.

VALlADARES, F. (2004): Ecología del bosque mediterráneo en un mundo cambiante. Ministerio de Medio Ambiente. Madrid.

VeRHUlST, J., BÁLDI, A. y KLEIJN, D. (2004): «Relationship between land-use intensity and species richness and abundance of birds in Hungary» Agriculture, Ecosystems and Environment, 104, 465-473.

Vila, J., RiBAS, A., VARGA, D. y LlaUsás, A. (2009): «Medio siglo de cambios paisajísticos en la montaña mediterránea. Percepción y valoración social del paisaje en la alta Garrotxa (Girona)» Pirineos, vol 164, 69-92. Jaca. 